\title{
NUMERICAL EVALUATION OF BARELY VISIBLE IMPACT DAMAGE IN A CARBON FIBRE-REINFORCED COMPOSITE PANEL WITH SHEAR LOADING
}

\author{
JAKUB ŠEDEK \& PETR BĚLSKÝ \\ VZLU, Aerospace Research and Test Establishment, Prague, Czech Republic
}

\begin{abstract}
Impact by foreign objects is a concern for most composite structures, requiring attention in damage threat assessment. The purpose is to identify impact damage severity and detectability for design and maintenance. Barely visible impact damage (BVID) requires special treatment due to the difficulties in detecting it by any visual inspection method. BVID can reduce the load-carrying capability of a composite structure and, therefore, it can cause severe damage. The low-velocity impact causing BVID in a composite panel was studied via a numerical method using finite elements (FEs) with the explicit dynamic integration method. A ply-by-ply three-dimensional model with cohesive zone behavior of interaction was created, enabling a detailed study of material degradation through composite thickness. Two cases with double impact and with no impact were analyzed. Impacts directed near the hole's edge caused delamination and ply degradation. Subsequently applied shear loading shows the impact influence on the strength of the panel. The numerical results confirm a decrease in the strength of the composite panel after impact, as expected, but differences in displacement behavior were also observed. According to the FE solution, buckling appears in regions of impact before rupture, while test results reported rapid failures in the compression zone and tension zone, independently, in two stages. On the other hand, the FE results of the non-impacted panel show two independent failures, as observed experimentally. As a result, the unrealistic buckling is attributed to a decrease in element stiffness during impact. In conclusion, the final strength of the impacted panel was predicted by the FE solution sufficiently. The BVID modelling approach presented in this study is useful in the case of small-scale models such as a flat panel. The research has received funding from the European Union's Seventh Framework Programme for Research, Technological Development and Demonstration within CANAL (CreAting NonconventionAl Laminates) project under grant agreement number 605583.

Keywords: composite panel, FEM, impact, shear loading.
\end{abstract}

\section{INTRODUCTION}

The application of composites in structures which are operated under a damage-tolerance philosophy requires various procedures during the design, manufacture and service stages in order to ensure structural integrity under various conditions. Static and fatigue strength evaluation is an integral part of each developing process. A significant aspect in damagetolerance philosophy is demonstrating that impact damage, which can be likely expected at the manufacturing and service stages, will not reduce the structural strength below ultimate load capability. This can be shown by analysis supported by test evidence, or by a combination of tests at the coupon, element, subcomponent, and component levels [1].

In-service damage can be expected mostly in dimensions which are barely visibly detectable. When using a visual inspection procedure, the likely impact damage at the threshold of reliable detection has been called barely visible impact damage (BVID). BVID is caused mostly by low-velocity impact during service; for example, tool drop, handling accidents, collision with foreign objects, etc. The danger of BVIDs is the damage caused under the surface, which is not easily detectable by visual inspection, and other nondestructive detection techniques should be employed [2], [3]. 
The damage zone of a composite caused by an impact is generally complex in nature and very difficult to characterize. The speed of an impact should be related to the vibrational response of a composite. When the contact time between the impactor and the composite is longer than the time for the lowest vibration mode, than low-velocity impact occurs. Boundary conditions are related to the vibrational response of the element; stress waves generated at the impact point can reach the edges of the element and cause a full-vibrational response. In contrast, a high-velocity impact is a local phenomenon in the neighborhood of the impacted zone and is generally independent of the element's boundary conditions. The contact period of the impactor is much smaller than the time period of the lowest vibrational mode of the structure [4].

Damage to a composite caused by low-velocity impact is commonly the mixture of interlaminar failure (delamination), intra-ply microcracks, matrix microcracking and backface tension-driven fiber failure. In the beginning, the failure process develops as matrix cracking or fiber splitting, resulting in initial delamination. Once the bending strains are high enough, fiber fracture occurs and delamination propagates.

Finite element (FE) analysis is widely used in order to evaluate the quality of a structure to sustain BVID and to determine subsequent load capability. Composite plates can be simulated as layered two-dimensional anisotropic plates if there are no significant throughthickness stresses. During normal point impact, these stresses rise and a three-dimensional concept of thin, even plates with interlaminar stresses among them shall be applied [5]-[7]. In order to cover composite damages computationally it is useful to divide them according to the location where they occur [5], [8]:

- Translaminar damages, i.e. fiber breakages;

- Intralaminar damages, i.e. damages developing inside the ply (matrix cracking, fiber/matrix debonding);

- Interlaminar damages, i.e. damages developing at the interface between two consecutive plies (delamination).

Suitable FE model capabilities shall be used. An interface element or interaction property is necessary to simulate delamination and degradation of the interface. A damage model of a ply should involve the degradation of its stiffness and strength evaluation, preferably according to the failure mode either by matrix cracking or fiber breakage. A coupling between the intra and inter ply damages is also necessary.

The above-mentioned assumptions were taken into account when building the FE model of the tested specimen - a panel with a large centered hole.

\section{ANALYSIS CONCEPT AND DETAILS}

A composite panel, $3.4 \mathrm{~mm}$ thick, made from carbon fibers T700GC and RTM6 resin matrix was simulated. The panel was originally manufactured using the automated tape-laying technique by cladding $150-\mathrm{mm}$-wide tapes. Unidirectional plies are stacked in 24 layers with the stacking sequence [45/-452/45/90/-45/452/-45/90/-45/45]s. Square panels with a side dimension of $234 \mathrm{~mm}$ and a large hole measuring $40 \mathrm{~mm}$ in diameter placed in the center were manufactured originally. After impact, a reinforced rim for the shear rig attachment was added.

The process of strength evaluation can be split into two stages, which are taken specifically from the simulation point of view. The first stage is double low-velocity impact $(v=10 \mathrm{~m} / \mathrm{s})$ and the second stage is subsequent shear loading (see Fig. 1). Simulation can be taken also accordingly. Low-velocity impacts cause the development of a damaged zone in the vicinity of impact points and shear loading is applied to evaluate the strength influenced 
by the BVID created. If impact time is much longer than the time for elastic waves to reach element boundaries, the structure response is quasi-static and impact can be treated as a quasistatic problem. Deflection and load would have a similar relation as that in static loading and an implicit integration scheme can be conveniently applied [3]. However, sophisticated FE models can produce slow stability of the solution (e.g. due to interactions among plies) and therefore, the explicit dynamic integration method could be used, as in the presented problem.

\subsection{Numerical model of composite panel}

The simulation of the problem is performed in ABAQUS 6.13.2 FE code. The model is assembled from 24 plies created from continuum shell elements with the thickness property of $0.142 \mathrm{~mm}$ each. Due to the alternating direction of plies and non-centered impact locations, we were unable to apply any symmetry and the whole model of the panel was analyzed (see Fig. 2). The mesh of the model consists of a total of 60,000 elements.

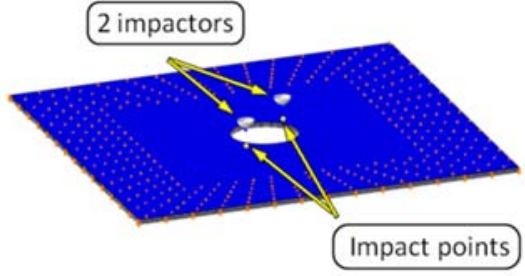

(a)

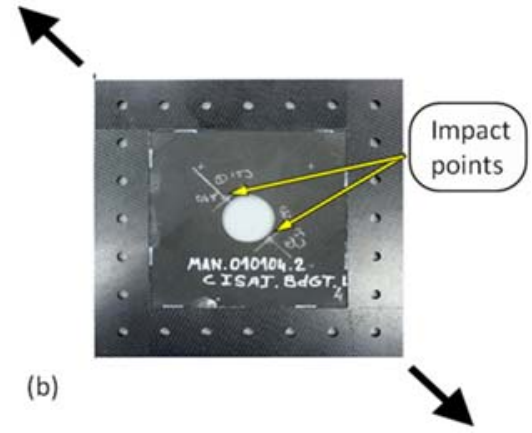

(b)

Figure 1: Two stages of strength evaluation of the panel with BVID. (a) Double lowvelocity impact; (b) Shear loading.

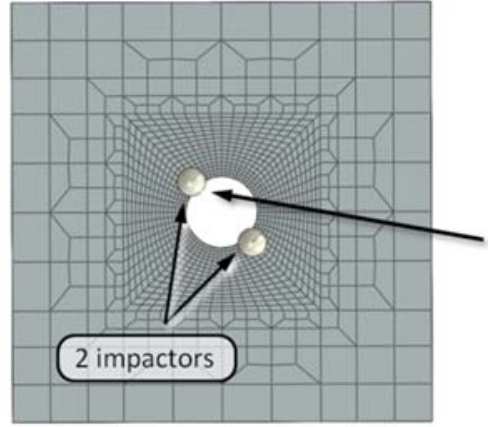

(a)

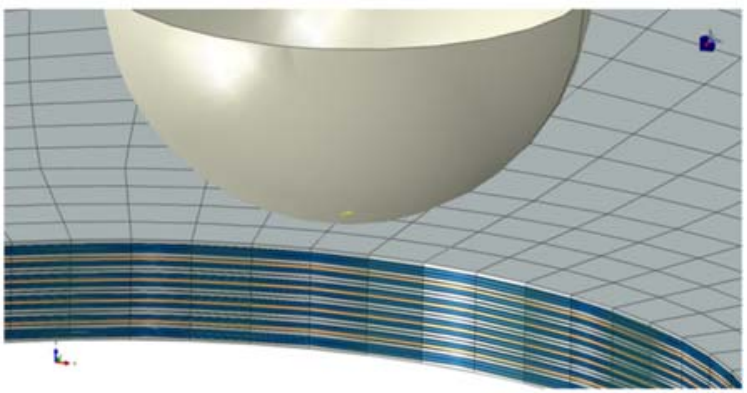

(b)

Figure 2: $\quad$ FE model of the panel. (a) General view on the panel; (b) Detailed view of the impact area. Different ply orientations are highlighted by different colors. 
The ply properties are described by orthotropic material, but through-thickness behavior is not taken into account. This assumption, as discussed above, can be made based on the reason that the present impact stage comprises low-velocity and deflection-driven phenomena. Ply damage is implemented according to Hashin and Rotem [9] who evaluate four separate failure modes for:

- $\quad$ fibers in tension $\left(\hat{\sigma}_{11} \geq 0\right)$

$$
F_{f}^{t}=\left(\frac{\widehat{\sigma}_{11}}{X^{T}}\right)^{2}+\left(\frac{\hat{\tau}_{12}}{S^{L}}\right)^{2},
$$

- $\quad$ fibers in compression $\left(\hat{\sigma}_{11}<0\right)$

$$
F_{f}^{c}=\left(\frac{\widehat{\sigma}_{11}}{X^{C}}\right)^{2}
$$

- $\quad$ matrix in tension $\left(\hat{\sigma}_{22} \geq 0\right)$

$$
F_{m}^{t}=\left(\frac{\widehat{\sigma}_{22}}{Y^{T}}\right)^{2}+\alpha\left(\frac{\hat{\tau}_{12}}{s^{L}}\right)^{2}
$$

- matrix in compression $\left(\hat{\sigma}_{22}<0\right)$

$$
F_{m}^{c}=\left(\frac{\widehat{\sigma}_{22}}{2 S^{T}}\right)^{2}+\left[\left(\frac{Y^{C}}{2 S^{T}}\right)^{2}-1\right]\left(\frac{\widehat{\sigma}_{22}}{Y^{C}}\right)^{2}+\left(\frac{\hat{\tau}_{12}}{S^{L}}\right)^{2}
$$

where $\hat{\sigma}_{i i}$ or $\hat{\tau}_{i i}$ are the stress components in directions $i i, X^{T} / X^{C}$ is the longitudinal ply strength in tension/compression, $Y^{T} / Y^{C}$ is the transverse ply strength in tension/compression and $S_{L}$ is the shear strength in the ply plane. Damage evolution is described by reducing the stiffness in elastic matrix $\boldsymbol{C}_{\boldsymbol{D}}$ and resulting stress $\boldsymbol{\sigma}$ is computed according to eqn (5) from strains $\boldsymbol{\varepsilon}$.

$$
\boldsymbol{\sigma}=\boldsymbol{C}_{\boldsymbol{D}} \boldsymbol{\varepsilon}
$$

The ply material properties are summarized in Table 1 .

The interface between plies is represented by cohesive elements with zero thickness. Interply elements have cohesive behavior described by the cohesive zone model (CZM) in order to enable the separation of plies during impact and loading. Physically, the cohesive zone represents the coalescence of crazes in resin rich layer located at delamination front and simulates the process by which the material loses load-carrying capacity. Displacement of the connected nodes on plies is driven by the traction separation law, with three major characteristics in the phases of:

- $\quad$ pre-damage response - cohesive stiffness $K_{n}, K_{s}, K_{t}$;

- damage initiation - cohesive strength $t_{n}^{0}, t_{s}^{0}, t_{t}^{0}$;

- damage evolution - fracture toughness $G I_{C}, G I I_{C}, G I I I_{C}$.

Table 1: Ply material properties.

\begin{tabular}{|l|l|l|l|l|l|}
\hline$E_{11}[\mathrm{MPa}]$ & $E_{22}[\mathrm{MPa}]$ & $v_{12}[-]$ & $G_{12}[\mathrm{MPa}]$ & $G_{13}[\mathrm{MPa}]$ & $G_{23}[\mathrm{MPa}]$ \\
\hline 110000 & 7400 & 0.3 & 4200 & 4200 & 4200 \\
\hline$X^{T}[\mathrm{MPa}]$ & $X^{C}[\mathrm{MPa}]$ & $Y^{T}[\mathrm{MPa}]$ & $Y^{C}[\mathrm{MPa}]$ & $S^{L}[\mathrm{MPa}]$ & $S^{T}[\mathrm{MPa}]$ \\
\hline 2300 & 1500 & 66 & 220 & 93 & 93 \\
\hline
\end{tabular}


The pre-damage response of the interlaminar interface is driven by stiffness $K_{i}$, where $i$ corresponds to normal direction $n$ and tangential directions $s$ and $t$. Interlaminar stiffness should be large enough to maintain a reasonable stiffness but small enough to avoid numerical problems. Some authors have also proposed the definition as a function of the interface thickness, and elastic moduli of the interface [10], [11]. The chosen value of interlaminar stiffness in all directions is $10^{6} \mathrm{~N} / \mathrm{mm}^{3}$ so that the stiffness is in a higher order than the stiffness of the connected elements, according to Camanho et al. [11], [12]. Once the interlaminar interface is broken, all initial stiffnesses $K_{i}$ are set to zero and the contact problem is addressed by applying normal penalty stiffness when penetration of plies is detected.

The damage initiation of the inter-ply interface depends on interlaminar strength in normal direction $t_{n}^{0}$, and tangential directions $t_{s}^{0}$ and $t_{t}^{0}$. Coupling is incorporated according to quadratic failure criterion (eqn (6)), where $t_{n}, t_{s}$ and $t_{t}$ denote actual tractions. Macaulay brackets \langle\rangle acting on $t_{n}$ means, that compressive normal tractions do not affect delamination onset. Interactive failure criteria should generally predict the delamination failure stress better than non-interactive criteria; for example, evaluating maximum traction in each direction separately, because interactive criteria are mostly curve fitting in nature [13].

$$
\left(\frac{\left\langle t_{n}\right\rangle}{t_{n}^{0}}\right)^{2}+\left(\frac{t_{s}}{t_{s}^{0}}\right)^{2}+\left(\frac{t_{t}}{t_{t}^{0}}\right)^{2}=1
$$

Damage evolution depends on fracture toughness $G_{C}$ expressed in respective separates modes $I, I I$ and III. Fracture toughness can be shown in relation to the traction versus displacement curve, known as "traction-separation law", as the area under that curve. The basic behavior of the used law is bi-linear, softening constitutive behavior. The separation at complete decohesion (displacement $\delta_{i}^{f}$ ) can be expressed in the relation eqn (7) as $\delta_{n}^{f}=$ $2 G_{I C} / t_{n}^{0}, \delta_{t}^{f}=2 G_{I I C} / t_{s}^{0}$ and $\delta_{s}^{f}=2 G_{I I I C} / t_{t}^{0}$, where $\tau_{i}$ denotes the traction in direction $i$ and $d \delta_{i}$ denotes the infinitesimal increment of displacement $\delta_{i}$ :

$$
\begin{array}{ll}
\int_{0}^{\delta_{i}^{f}} \tau_{i} d \delta_{i}=G_{j C} ; \text { for } \quad \begin{array}{l}
i=n, j=I \\
i=s, j=I I \\
i=I I
\end{array} .
\end{array}
$$

Once cohesive strength is reached, damage evolution is taken into account. Traction components $t_{i}$ are determined according to eqns (8)-(10), applying damage parameter $D$, which is the function of traction-separation law. The upper sign - denotes the traction derived from initial stiffness:

$$
\begin{gathered}
t_{n}=\left\{\begin{array}{c}
(1-D) \bar{t}_{n}, \bar{t}_{n}>0 \\
\bar{t}_{n}
\end{array}\right. \\
t_{s}=(1-D) \bar{t}_{s}, \\
t_{t}=(1-D) \bar{t}_{t}
\end{gathered}
$$

The softening process after damage initiation is also driven by the combination of separate modes according to the direction of separation. The mixed-mode criterion proposed by Benzeggagh and Kenane [14] combines energy release rates and fracture toughness 
according to eqn (11), where $G_{T}=G_{I}+G_{\text {shear }}$ and $\eta$ should be determined from a mixedmode bending (MMB) test at different mode rations. $\eta=2$ is used here according to the parameter review presented in Camanho and Dávila [15].

$$
G_{I C}+\left(G_{I I C}-G_{I C}\right)\left(\frac{G_{\text {shear }}}{G_{T}}\right)^{\eta}=G_{C}
$$

Fracture toughness in mode III is very difficult to measure experimentally, since no standard is released; therefore, most of the failure criteria proposed for delamination growth were established for mixed-mode $I$ and $I I$ loading only. Components of loading related to shear are often summed together as in this work: $G_{\text {shear }}=G_{I I}+G_{I I I}$.

Implementing CZM into a model of complex structure requires a tuning process of CZM sensitivity to the mesh and internal parameters. Double cantilever beam (DCB), end notch flexure (ENF) and MMB specimens are commonly used. The inter-ply properties of CZM which were used in the analysis are summarized in Table 2.

\section{ORIGINATION OF BARELY VISIBLE IMPACT DAMAGE (BVID): IMPACT STAGE OF THE ANALYSIS}

Damage of the composite in the first stage of the test and also of the FE analysis is caused by double low-velocity impact. An impactor with the velocity of $10 \mathrm{~m} / \mathrm{s}$ was directed near the edge of the large hole at the diagonal and the second impact was directed at the opposite location of the hole on the same diagonal. The energy of each impact was chosen as $15 \mathrm{~J}$. During the impact, the panel was supported at its ends all around the perimeter, but was not clamped in order to allow the free displacement of ends in the normal direction of the panel plane.

At the beginning of the impact, after the first touch of the impactor and the top ply, top layers are pressed down and the transfer of kinetic energy into the composite begins. The velocity of the impactor is gradually reduced to zero and then the impactor is bounced back. No full penetration through the composite occurs and only partial penetration was allowed. Layers hit by the impactor are situated in the top half of the composite thickness, where most of the delamination also occurs. The phases of impact are shown in Fig. 3. The second case of impact is almost identic; therefore, both impacts can be treated independently under the boundary conditions currently applied.

Damaged zone in a ply can be evaluated by displaying maximum damage initiation value (DMICRTMAXVAL [16]) as shown in Fig. 4. In the top layers, damage develops mostly in the direction perpendicular to fibers, around the middle of the thickness damage is concentrated under the impact point and it is not spread further. In bottom layers, damage caused by the rectangular support is visible.

Table 2: Ply interlaminar interface properties.

\begin{tabular}{|l|l|l|l|l|l|}
\hline $\begin{array}{l}t_{n}^{0} \\
{\left[\mathrm{~N} / \mathrm{mm}^{3}\right]}\end{array}$ & $\begin{array}{l}t_{s}^{0} \\
{\left[\mathrm{~N} / \mathrm{mm}^{3}\right]}\end{array}$ & $\begin{array}{l}t_{t}^{0} \\
{\left[\mathrm{~N} / \mathrm{mm}^{3}\right]}\end{array}$ & $\begin{array}{l}G_{I C} \\
{[\mathrm{~kJ} / \mathrm{mm}]}\end{array}$ & $\begin{array}{l}G_{\text {IIC }} \\
{[\mathrm{kJ} / \mathrm{mm}]}\end{array}$ & $\begin{array}{l}G_{\text {IIIC }} \\
{[\mathrm{kJ} / \mathrm{mm}]}\end{array}$ \\
\hline 12 & 20 & 20 & 0.9 & 1.8 & 1.8 \\
\hline
\end{tabular}



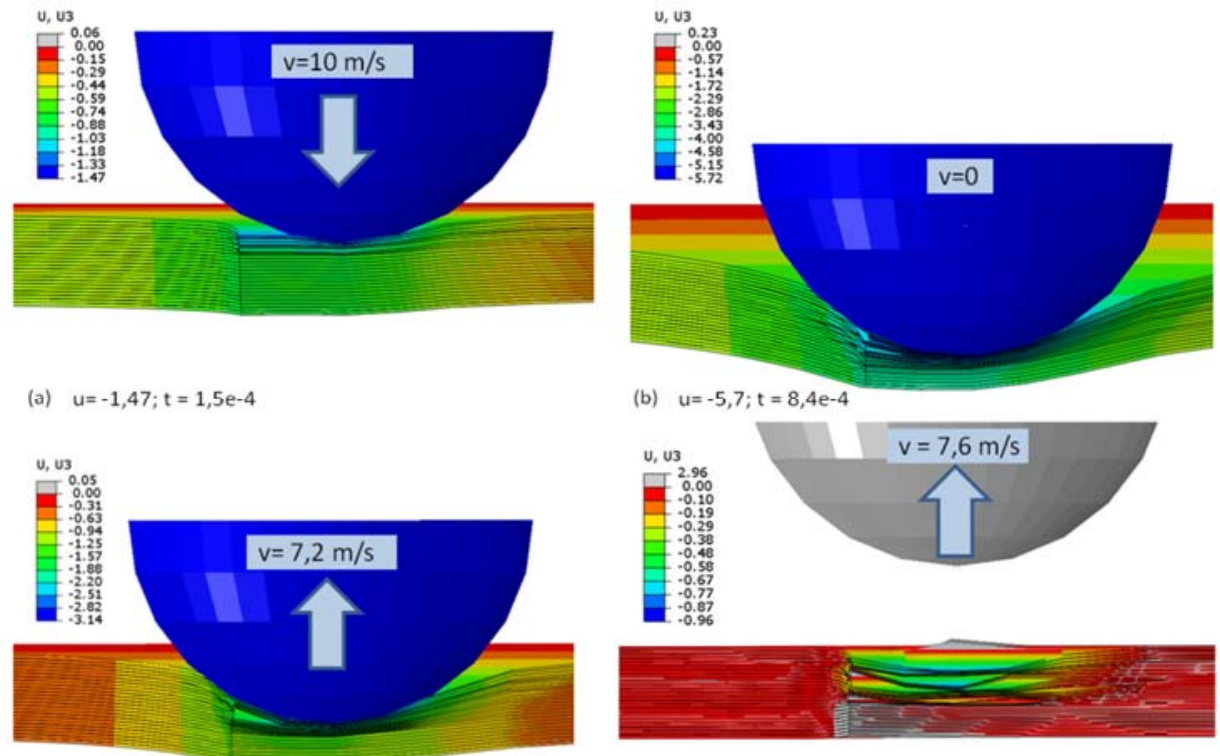

(b) $u=-5,7 ; t=8,4 e-4$

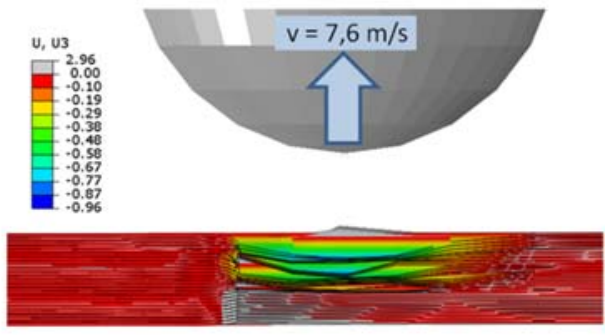

(c) $u=-3,14 ; t=1,5 \mathrm{e}-3$

(d) $u=2,96 ; t=2,3 e-3$

Figure 3: Impact stage in FE analysis. Impactor displacement $=\mathrm{u}$, time after touching the top ply = t. (a) Initial contact; (b) Pressing down; (c) Bouncing; (d) Inverse moving.

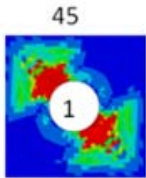

45

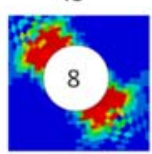

45

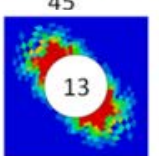

90

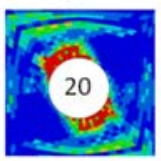

(a)

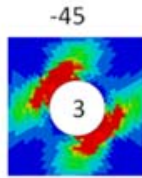

90

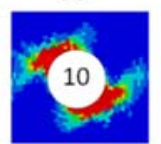

90

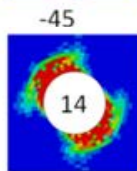

45

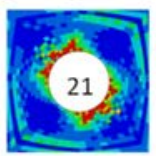

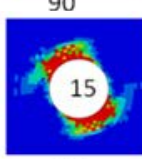

$-45$

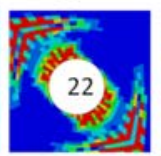

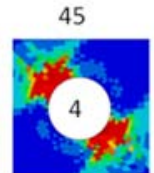

$-45$

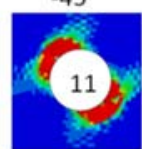

$-45$

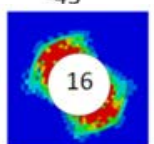

$-45$

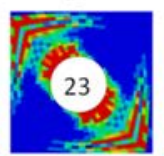

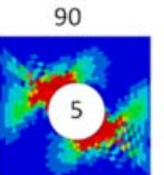

45

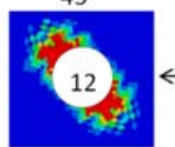

45

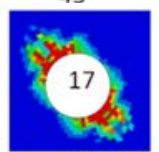

45

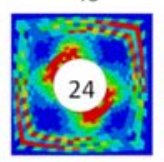

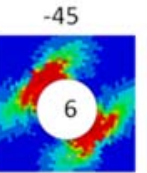
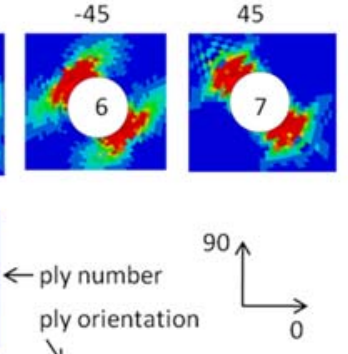

$\downarrow_{45}$

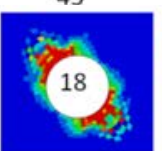

DMICRTMAXVAL

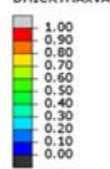

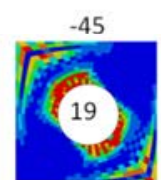

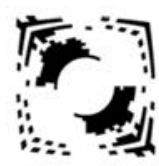

(b)

Figure 4: Damage of plies caused by two impacts evaluated by maximum damage initiation value (DMICRTMAXVAL); FE analysis. (a) Separate plies; (b) All plies together. Black color - DMICRTMAXVAL $=1$. 
According to the ply damage visualization, the delamination between plies is also presented (see Fig. 5). Cohesive zone modelling is used for ply interaction, which incorporates damage development. Cohesive status can be evaluated using damage parameters (CSDMG [16]) which takes the value of 1 if total interaction failure occurs. Practically, it is necessary to assume the limit of CSDMG value due to a very low rate of damage grow when reaching the limit value of 1 . The limit of 0.999 was used in the present delamination area's evaluation.

The delamination area grows in depth in several similar zones. The first grows up to the sixth ply interface, the second up to the eleventh ply interface, whereas the both of them are the same size. The third develops up to the sixteenth ply interface, also from the similar size at the top, but the development is not so obvious. The remaining ply interfaces do not show any clear signs of size growth in depth. There is a unique cone-like shape development of delamination with depth. In Fig. 5, the interface sequences between plies 1-7, 7-12 and $12-17$ can be seen. The largest delaminated areas are developed among ply sequences 90/-45/45 (plies 5-7, 10-12 and 15-17) followed by the minimum area of the next cone-like shape of delamination. To conclude, between plies with the same orientation, very weak delamination transfer occurs (plies 7-8, 12-13 and 17-18), acting as stoppers for the conelike shape development. This phenomenon is not so clear at the top and bottom layers, probably due to the free surface vicinity.

The top view of delamination through layers was compared with observations using ultrasonic investigation, which allows to identify each interface. The C-Scan should give supplementary information on the delamination shape and, in particular, the exact shape of the first interface from the top. Nevertheless, the resolution of the ultrasonic probe was not satisfactory due to the input pulse width and so only damages starting at $1.5 \mathrm{~mm}$ under the top surface were available for investigation; note, the total thickness of the composite is $3.4 \mathrm{~mm}$. However, the total delaminated area through the thickness was determined as shown in Fig. 6. The dimensions of the delaminated area correspond very well with the FE solution and it is shown that the delamination caused by the first and second impacts are the same.

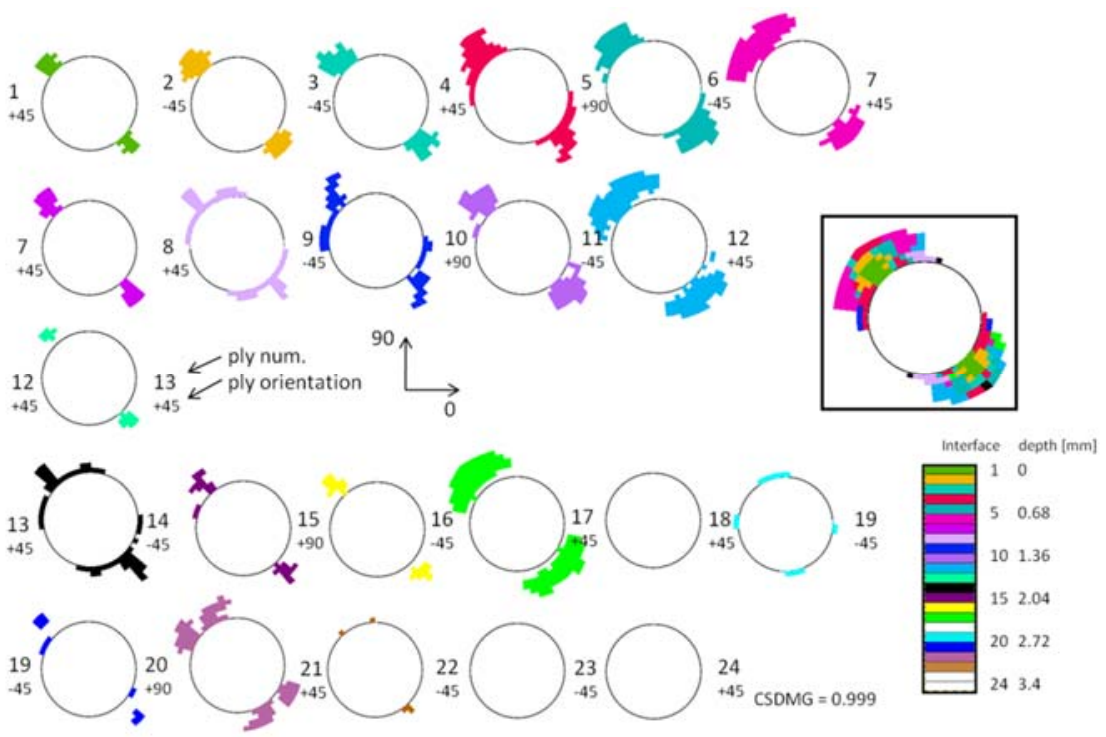

Figure 5: Delamination between plies caused by two impacts; FE analysis. 

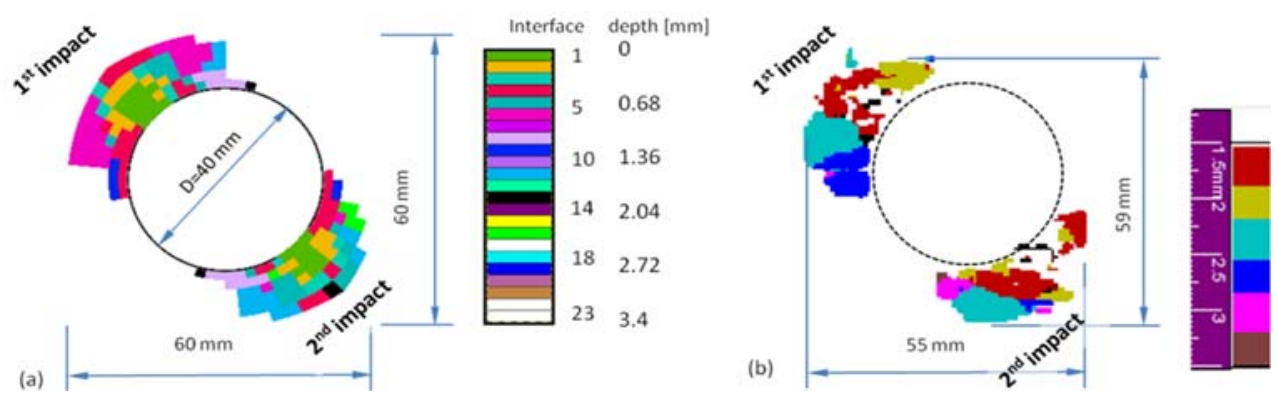

Figure 6: Delamination according to depth. (a) FE analysis; (b) Ultrasonic experimental investigation (C-Scan).

Both FE analysis and C-Scan confirm the hypothesis that both impacts are independent of each other; that is, the impacts have no (or very small) influence on the damage development on the opposite side of the hole.

\section{STRENGTH OF THE PANEL WITH BVIDS AND WITHOUT THEM: SHEAR LOADING STAGE OF THE ANALYSIS}

The second phase of strength evaluation of the panel with BVIDs deals with shear loading. The panel is loaded so that BVIDs caused by impacts are situated in compression diagonal zones (see Fig. 1). In the second diagonal, tension loading appears. The principle can be easily understood from the idea of corner-loaded rectangular which is reinforced in diagonals. The diagonal perpendicular to the loading direction is loaded in compression and the diagonal parallel with loading is loaded in tension. The following paragraph demonstrates the behavior during shear loading of the panel without BVID.

The response of the panel to shear loading is linear up to the first failure in the compression diagonal. The failure begins at the edge of the large hole and rapidly expands over the whole diagonal, but the panel is still able to carry load over the tension diagonal, which subsequently fails under continual loading (see Fig. 7). The FE solution yields oscillations after compression failure, but this is related to the solver nature using the explicit dynamic integration method. Total damage is localized in both diagonals.

The initial part of shear loading of the panel including two BVIDs looks similarly up to $90 \mathrm{kN}$ where the decay of the stiffness begins. From this point, the buckling of plies in the BVID zone (compression zone) develops up to $130 \mathrm{kN}$ and afterwards damage continuously increases up to $160 \mathrm{kN}$ when full compression diagonal fails. Following loading is linear up to the sharp failure occurring in the tension diagonal at $183 \mathrm{kN}$.

Obvious differences in the loading behavior of the panel with and without BVIDs are found in the development of the first compression failure. FE analysis shows plies buckling and continuous development of the damage contrary to experimental observation. Several specimens with BVID were tested under shear loading and all specimens failed suddenly in compression and subsequently in tension. The FE model with BVID behaves differently in compression failure, although the load level when buckling begins is close to experimental compression failure. The load level at failure in the tension diagonal is the same.

\section{CONCLUSION}

The numerical strength evaluation of a composite panel with a large hole with BVIDs on its edge was presented. A ply-by-ply FE model of the composite panel was created and 


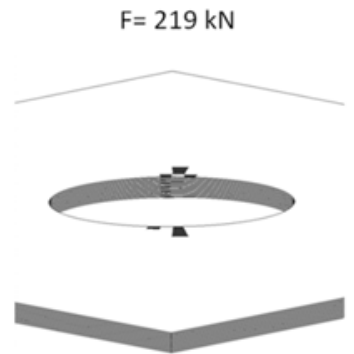

(a)

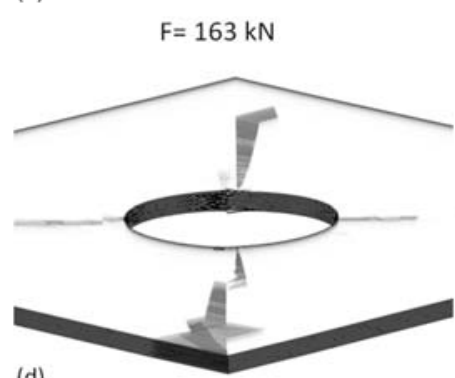

(d)

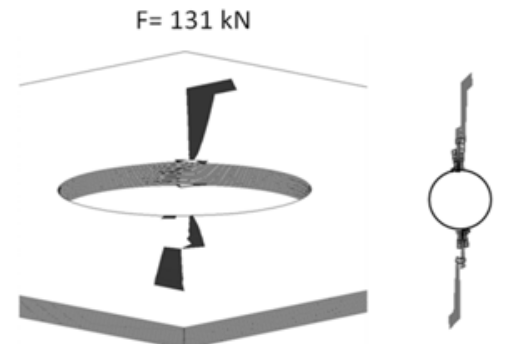

(c)

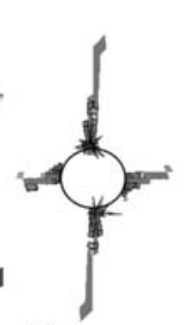

(e)

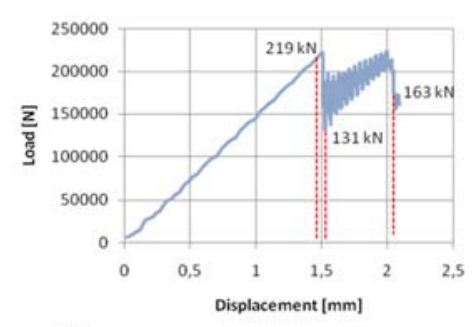

(f)

Figure 7: Shear loading of the panel without BVID; FE analysis. (a) Damage at $219 \mathrm{kN}$; (b) Damage at $131 \mathrm{kN}$; (c) Top view on the damage at $131 \mathrm{kN}$; (d) Damage at $263 \mathrm{kN}$; (e) Top view on the damage at $163 \mathrm{kN}$; (f) Load-displacement diagram.

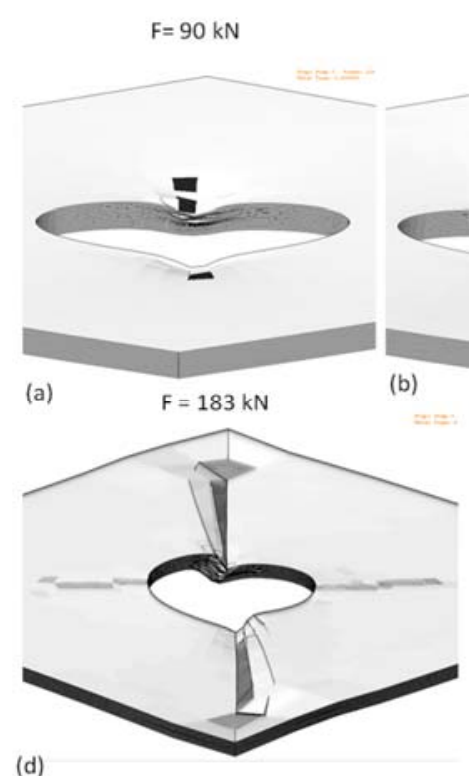

(d)
$\mathrm{F}=130 \mathrm{kN}$

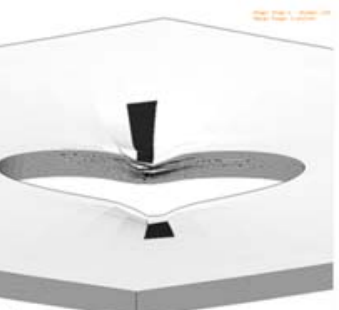

(b)

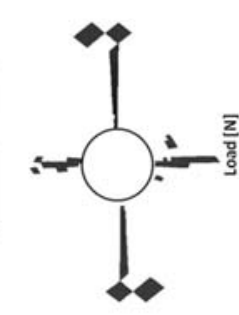

(e)

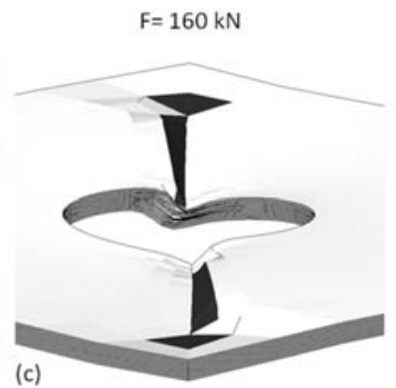

(c)

Figure 8: Shear loading of the impacted panel including BVID; FE analysis. (a) Damage at $90 \mathrm{kN}$; (b) Damage at $130 \mathrm{kN}$; (c) Damage at $160 \mathrm{kN}$; (d) Damage at $183 \mathrm{kN}$; (e) Top view on the damage at $183 \mathrm{kN}$; (f) Load-displacement diagram. 

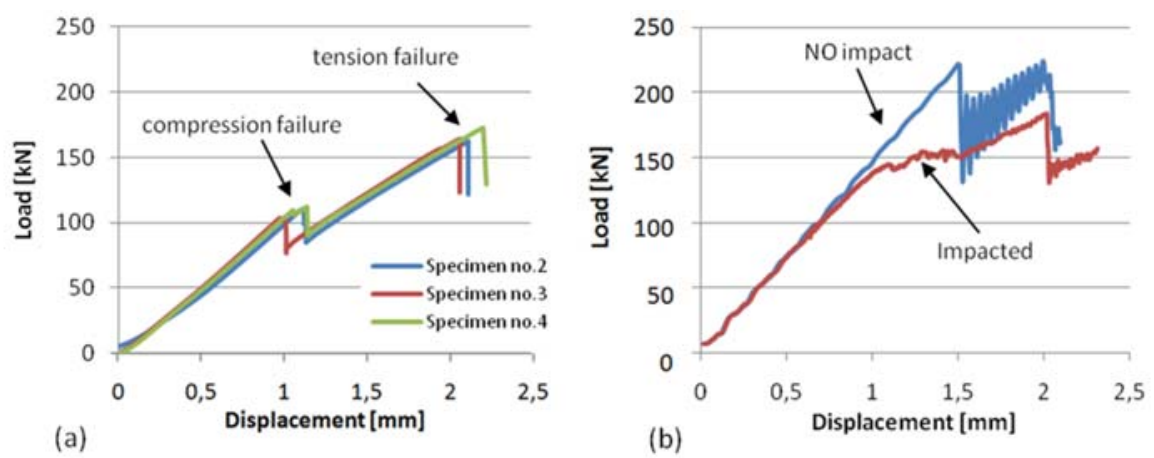

Figure 9: Load-displacement curves of composite panel. (a) Experimental results of impacted panels; (b) Results of FE analysis of impacted and non-impacted panels.

analyzed. Ply damage and inter-ply damage was taken into account. The analysis was split into two stages: double impact and shear loading. The damage and delamination of plies were evaluated and the complex response was displayed in a load-displacement curve. The panel with BVIDs was compared with a damage-free panel.

Based on the results of the impact phase, it was shown that low-velocity impacts with $15 \mathrm{~J}$ energy, each acting on opposite sides of the large hole, are in analyzed configurations, independent of each other. BVIDs caused by the impact near the edge of the large hole can be created independently on the opposite BVID, and the order of impacts is irrelevant.

The impact causes cone-like shape delamination through the thickness. This cone-like shape is obvious in three steps with 5-6 plies included and it is terminated by the interface between the ply with a $45^{\circ}$ orientation, followed by a ply also with a $45^{\circ}$ orientation. Ply damage develops in upper plies primarily in the direction perpendicular to fiber orientation. In lower plies, although not so obvious, damage from the support appears. In spite of evaluating the damage of plies and delamination separately, the damage of the panel should be treated as the combination of both - ply damage and delamination. Both types of damage influence each other and must be treated together.

The analysis of the shear strength of the panel with BVID showed buckling behavior in the compression zone located inside the BVID. The load level of buckling initiation is close to the experimental load level of the sudden compressive failure. According to the analysis, after gradual damage development in the whole compression diagonal, the sudden failure in the tension diagonal occurs at the exact load level as in the experiment.

The development of the compressive damage and failure is diametrically different in experimental observation and FE analysis, in spite of the fact that the comparison of BVIDs caused by impacts is satisfactory. It is obvious that the intralaminar failure criterion used in conjunction with the present FE model are not capable of covering the damage found in the compressed BVID zone. In a subsequent investigation, a more sophisticated model of ply damage should be employed; for example, LARC03, LARC04 [17], which take into account fibers microbuckling in compression.

The presented approach to numerically assess BVID is useful in small-scale models like flat panels. Its application to large composite structures is not suitable in spite of a continuous increase in the computational capacity of desktop stations and computational clusters. The analysis is practically executable on cut-outs of interested structures in the vicinity of the 
impact zone with boundary conditions adopted according to the classical solution of the composite structure using one shell element through the thickness.

\section{ACKNOWLEDGEMENT}

This research received funding from the European Union's Seventh Framework Programme for Research, Technological Development and Demonstration within the CANAL (CreAting NonconventionAl Laminates) project.

\section{REFERENCES}

[1] Averay, J.G., Design Manual for Impact Damage Tolerant Aircraft Structure, AGARD-AG-238, 1981, ISBN 92-835-1403-3.

[2] Kadlec, M. \& Růžek, R., A comparison of laser shearography and C-Scan for assessing a glass/epoxy laminate impact damage. Applied Composite Materials, 19, pp. 393-407, 2012.

[3] Michalcová, L. \& Kadlec, M., Carbon/epoxy composite delamination analysis by acoustic emission method under various environmental conditions. Engineering Failure Analysis, 69, pp. 88-96, 2016.

[4] Razali, N., Sultan, M.T.H., Mustapha, F., Yidris, N. \& Ishak, M.R., Impact damage on composite structures - a review. The International Journal of Engineering and Science, 3, 2006. ISSN 2319-1805.

[5] Bouvet, Ch., Castanié, B., Bizeul, M. \& Barrau, J.J., Low velocity impact modelling in laminate composite panels with discrete interface elements. International Journal of Solids and Structures, 46, pp. 2809-2821, 2009.

[6] Bouvet, C., Rivallant, S. \& Barrau, J.J., Low velocity impact modeling in composite laminates capturing permanent indentation. Composites Science and Technology, 72(16), pp. 1977-1988, 2012.

[7] Shi, Y., Pinna, C. \& Soutis, C., Low-velocity impact of composite laminates: damage evolution. Dynamic Deformation, Damage and Fracture in Composite Materials and Structures, ed. V. Silberchmidt, Woodhead Publishing, pp. 117-144, 2016, ISBN 9780-08-100870-6.

[8] Greengalgh, E.S., Failure Analysis and Fractography of Polymer Composites, 1st ed., Woodhead Publishing: Cambridge, 2009.

[9] Hashin, Z. \& Rotem, A., A fatigue criterion for fiber-reinforced materials. Journal of Composite Materials, 7, pp. 448-464, 1973.

[10] Daudeville, L., Allix, O. \& Ladeveze, P., Delamination analysis by damage mechanics. Some applications. Composites Engineering, 5(1), pp. 17-24, 1995.

[11] Camanho, P.P., Dávila, C.G. \& de Moura, M.F., Numerical simulation of mixed-mode progressive delamination in composite materials. Journal of Composite Materials, 37(16), pp. 1415-1438, 2003.

[12] Camanho, P.P., Dávila, C.G. \& Pinho, S.T., fracture analysis of composite co-cured structural joints using decohesion elements. Fatigue Fract Engng Mater Struct, 27, pp. 745-757, 2004.

[13] Cui, W., Wisnom, M.R. \& Jones, M., A comparison of failure criteria to predict delamination of unidirectional glass/epoxy specimens waisted through the thickness. Composites, 23(3), pp. 158-166, 1992.

[14] Benzeggagh, M.L. \& Kenane, M., Measurement of mixed-mode delamination fracture toughness of unidirectional glass/epoxy composites with mixed-mode bending apparatus. Composites Science and Technology, 56, pp. 439-449, 1996. 
[15] Camanho, P.P. \& Dávila, C.G., Mixed-Mode Decohesion Finite Elements for Simulation of Delamination in Composite materials, Langley Research Center, 2002, NASA/TM-2002-21173-211737.

[16] Dassault Systèmes, Abaqus 6.13 Online Documentation, 2013.

[17] Pinho, S.T, Dávila, C.G., Camanho, P.P., Ianucci, L. \& Robinson, P., Failure Models and Criteria for FRP Under In-Plane or Three-Dimensional Stress States Including Shear Non-Linearity, 2005, NASA/TM-2005-213530. 